\title{
Effect of Laser Therapy on Chronic Osteoarthritis of the Knee in Older Subjects
}

\author{
Enas Fawzey Youssef ${ }^{1}$, Qassim Ibrahim Muaidi ${ }^{2}$, Alsayed Abdelhameed Shanb ${ }^{1 *}$ \\ ${ }^{1}$ Department of Physical Therapy, College of Applied Medical Sciences, University of Dammam, Dammam, Saudi Arabia \\ ${ }^{2}$ Chairman of Physical Therapy Department; Vice Dean for Academic Affairs of College of Applied Medical Sciences, \\ University of Dammam, Dammam, Saudi Arabia
}

\author{
*Correspondence to \\ Alsayed Abdelhameed Shanb, MD \\ Department of Physical Therapy, \\ College of Applied Medical \\ Sciences, University of Dammam, \\ Saudi Arabia. \\ Tel: +96-6555786349; \\ Fax:+96-63330343 \\ Email: aashanb@uod.edu.sa
}

Published online 27 March 2016

\begin{abstract}
Introduction: Osteoarthritis $(\mathrm{OA})$ is a common degenerative joint disease particularly in older subjects. It is usually associated with pain, restricted range of motion, muscle weakness, difficulties in daily living activities and impaired quality of life. To determine the effects of adding two different intensities of low-level laser therapy (LLLT) to exercise training program on pain severity, joint stiffness, physical function, isometric muscle strength, range of motion of the knee, and quality of life in older subjects with knee OA.

Methods: Patients were randomly assigned into three groups. They received 16 sessions, 2 sessions/week for 8 weeks. Group-I: 18 patients were treated with a laser dose of $6 \mathrm{~J} / \mathrm{cm}^{2}$ with a total dose of $48 \mathrm{~J}$. Group-II: 18 patients were treated with a laser dose of $3 \mathrm{~J} / \mathrm{cm}^{2}$ with a total dose of $27 \mathrm{~J}$. Group-III: 15 patients were treated with laser without emission as a placebo. All patients received same exercise training program including stretching and strengthening exercises. Patients were evaluated before and after intervention by visual analogue scale (VAS), the Western Ontario and McMaster Universities Osteoarthritis (WOMAC) index for quality of life, handheld dynamometer and universal goniometer.

Results: $T$ test revealed that there was a significant reduction in VAS and pain intensity, an increase in isometric muscle strength and range of motion of the knee as well as increase in physical functional ability in three treatment groups. Also analysis of variance (ANOVA) proved significant differences among them and the post hoc tests (LSD) test showed the best improvements for patients of the first group.

Conclusion: It can be concluded that addition of LLLT to exercise training program is more effective than exercise training alone in the treatment of older patients with chronic knee $\mathrm{OA}$ and the rate of improvement may be dose dependent, as with $6 \mathrm{~J} / \mathrm{cm}^{2}$ or $3 \mathrm{~J} / \mathrm{cm}^{2}$.

Keywords: Laser therapy; Osteoarthritis; Life Quality.
\end{abstract}

\section{Introduction}

Osteoarthritis $(\mathrm{OA})$ is a degenerative joint disease ${ }^{1}$ which commonly affects weight bearing joints. The knee is the most common affected joint in the body, particularly in older subjects. ${ }^{2-4}$ Obesity, previous trauma, female gender and older age are considered the most common risk factors for knee OA. ${ }^{5}$ Knee OA is clinically associated with pain, restricted range of motion, and muscle weakness resulting in difficulties in daily living activities and impaired quality of life., ${ }^{2,6,7}$

Treatment of OA includes pharmacological and non-pharmacological modalities. ${ }^{8}$ Common targets of interventions are to alleviate pain, maintain physical function, and to prevent or postpone progression of adverse structural changes. ${ }^{9}$ Non-pharmacological treatment includes patients' education and physical therapy such as exercise training, phonophoresis, ultrasound, electromagnetic therapy, and transcutaneous electrical nerve stimulation, ${ }^{10,11}$ to relief pain and muscle spasm, reduce stiffness, and to strength weak muscles. ${ }^{10}$ Many factors may influence the responsiveness of the knee OA to physical therapy, e.g. mode of treatment delivery, treatment compliance issues and radiographic severity.

Recently, low-level laser therapy (LLLT) has been broadly used to control pain, ${ }^{1,12}$ and it has been recommended for its anti-inflammatory effects ${ }^{13,14}$ in addition to healing efficacy. ${ }^{2,15}$ LLLT has been used in a wide range musculoskeletal disorders such as cervical spondylosis, epicondylitis, low-back pain, ${ }^{16}$ and recently on knee OA. ${ }^{12,17,18}$ However, some studies have not been able to identify significant clinical benefits in some painful musculoskeletal conditions. ${ }^{16}$ In addition, other authors reported that LLLT had no effect on patients with knee OA. ${ }^{19}$

Despite widespread clinical application, results of experimental and clinical studies are still conflicting. ${ }^{20}$ Joints with OA showed considerable variation in response to LLLT. $^{17,20,21}$ However, there has been discrepancies in studies regarding the methods of application, treatment 
duration, dosage, and site of application..$^{17,18,20,21}$ Even when adding LLLT to exercise training in the treatment of $\mathrm{OA}$, there are still questions on their efficacy. ${ }^{21,22}$

The purpose of this study was to evaluate the effectiveness of adding LLLT with two common used intensities (6 J/ $\left.\mathrm{cm}^{2}\right)^{12,18}$ and $\left(3 \mathrm{~J} / \mathrm{cm}^{2}\right)^{23}$ to exercise training program in reducing pain intensity, improving range of motion, muscle strength and quality of life in older patients with chronic knee OA.

\section{Methods}

\section{Subjects}

Out of 80 patients evaluated, 20 were excluded, as they did not meet the inclusion criteria. Sixty older patients with knee OA were enrolled in this study from the outpatient clinic of the Faculty of Physical Therapy, Cairo-University (Figure 1).

\section{Inclusion Criteria}

Age 60 to 72 years; chronic knee OA according to American College of Rheumatology (ACR) criteria ${ }^{24}$; grades II \& III knee OA according to the Kellgren-Lawrence grades ${ }^{25}$; ability to stand independently and willingness to participate in the study.

\section{Exclusion Criteria}

Patients were excluded if they had concomitant disease affecting the knee, e.g. rheumatoid arthritis, recent injury, and/or surgery to the knee and had received intra-articular corticosteroid during the last 6 months. Patients were also excluded if he or she had history of cancer, dementia, neurological deficits, heart pacemaker, uncontrolled cardiovascular and metabolic diseases or morbid obesity ( body mass index $[\mathrm{BMI}] \geq 40$ ).

\section{Group-I}

Twenty older subjects were assigned to group-I, two dropped out at follow up, as they changed their address without notification. The follow up was for 18 (7 males \&
11 females) patients with a mean age of $67.3 \pm 2.9$ years. They were treated with a laser dose of $6 \mathrm{~J} / \mathrm{cm}^{2}$ over 8 points around the knee.

\section{Group-II}

Twenty older patients were assigned to group-II; two withdrew from follow up due to problems in transportations. Consequently, 18 ( 6 males \& 12 females) older patients with $67.5 \pm 2.5$ years mean age of were treated with a laser dose of $3 \mathrm{~J} / \mathrm{cm}^{2}$ on 9 points around the knee.

\section{Group-III}

Twenty older patients were assigned to group-III, five subjects were dropped; two because they preferred medications and three could not commit regularly to treatment sessions. Consequently, only 15 (5 males \& 10 females) older patients with a mean age of $(66.3 \pm 3.2)$ years participated as control group.

\section{Assessment Procedure}

Each patient was evaluated before and after 8 weeks of physical therapy interventions including:

\section{Pain Intensity}

Visual analogue scale (VAS) was used to evaluate pain; it is a reliable pain measure. It scored from 0 to $10 \mathrm{~cm}$, where 0 is pain free and 10 is maximal pain. ${ }^{26,27}$ Each patient was asked to mark a point on the line between 0 and 10 that related to his or her level of pain during the week of evaluation. ${ }^{28}$

\section{Physical Function}

It was evaluated using Western Ontario and McMaster Universities Osteoarthritis Index (WOMAC). It is a self-administered questionnaire used for assessment of physical function of patients. It is a reliable and valid outcome measure for evaluation of patients with hip and knee OA. ${ }^{19,29,30}$ Each patient was asked to give his or her response to pain intensity measures ( 5 items), joint stiffness ( 2 items), and physical function ( 17 items) through a 5-point scale $(0-4$, where: $0=$ no pain/limitation; $1=$ mild pain/limitation; $2=$ moderate pain/limitation; $3=$ severe

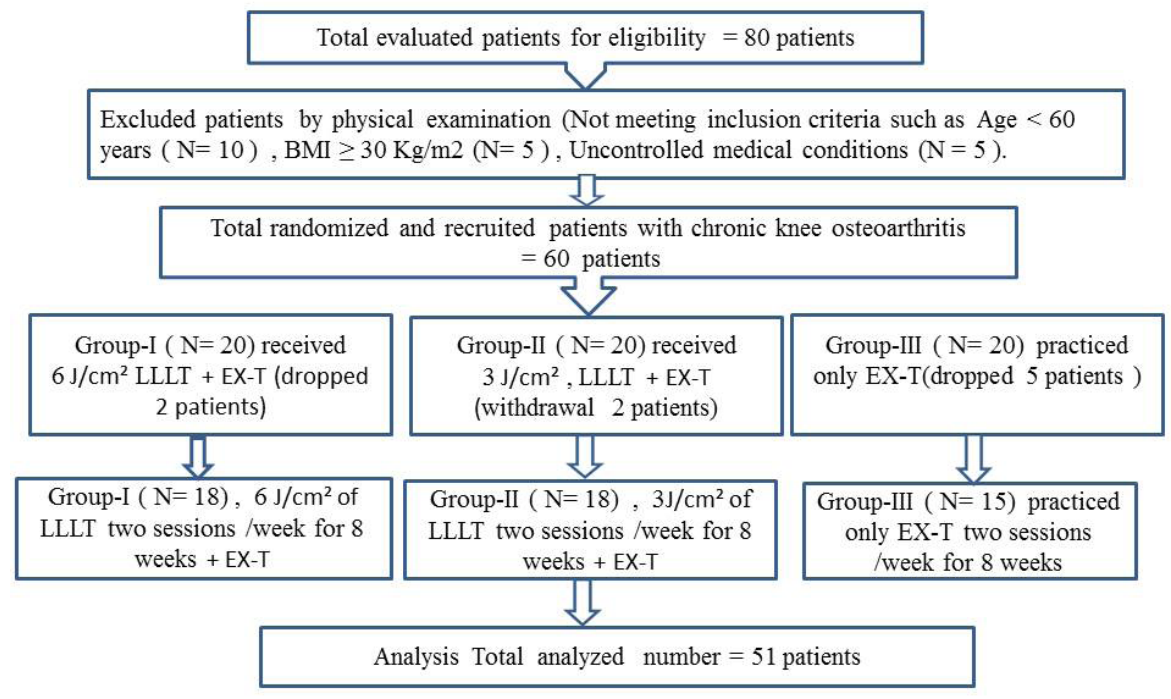

Figure 1. The Flow Diagram of Patients Recruitment. LLLT: low level laser therapy; EX-T, exercise training program; $\mathrm{J} / \mathrm{cm}^{2}$, laser dose by joules/square centimeter. 
pain/limitation; and 4 = extreme pain/limitation). Its maximal scores for pain, stiffness, and physical functions are 20,8 , and 68 , respectively. ${ }^{30}$ Total score of each category is separately summed up to give the final value of WOMAC sub-items. Lower scores indicate less pain, lower stiffness, high physical function, while higher scores indicate more pain, more stiffness low physical function (total scores of 96 indicating greater disease severities). ${ }^{19,29}$

\section{Knee Range of Motion}

Active flexion knee range of motion was measured with Long arm universal goniometer. It is a valid and reliable measure. ${ }^{31}$ It was evaluated from prone lying position, with extended knee; patients were asked to bring the heel of the tested leg as close as possible to the buttock while the other foot remained in contact with the plinth. The fulcrum of the goniometry on the lateral epicondyle of the femur of the tested knee with one arm in line with the lateral malleolus and the other arm in line with the greater trochanter. $^{32}$

\section{Isometric Muscle Strength}

Of the knee flexor and extensor muscles were measured using Handheld Dynamometer (MIE, Medical Research Ltd., England). ${ }^{33}$ Each patient performed knee flexion or extension for 5 repetitions as a warm up prior to the test. The maximal isometric muscle strength of knee flexor and extensor of the tested limb were measured for three trials. Mean values were calculated for each patient.

(a) Maximal knee extensors measurement: From a relaxed supine lying position with tested knee supported on small pillow and maintained in $60^{\circ}$ of flexion. The handheld dynamometer was placed against the anterior aspect of the leg away from the chin of tibia. Examiner stood on the contralateral side to tested knee. Correct starting position by adjusting the dynamometer before testing was determined. Each patient was asked to exert maximal force and push his or her leg up by performing knee extension against the probe of the hand dynamometer. The maximal isometric strength appeared automatically on the dynamometer screen. Mean values of three trials were calculated for each patient.

(b) Maximal knee flexor measurement: From a prone position with tested knee supported on a small pillow and maintained in $60^{\circ}$ of flexion. The handheld dynamometer was placed against the posterior aspect of the leg. Examiner stood on the side contralateral to tested knee. Correct starting position was determined by adjusting the dynamometer before testing. Each patient was asked to exert maximal force and push his or her leg up by performing knee flexion against the probe of the hand dynamometer. The maximal isometric strength appeared automatically on the dynamometer screen. ${ }^{33}$ Mean values of three trials were calculated for each patient.

\section{Treatment Procedure}

Group-I

After cleaning the skin with a piece of cotton to remove any dirt or grease in the treatment area, from relaxed supine lying position with slightly flexed knee supported on a small pillow, each patient received a LLLT dose of $6 \mathrm{~J} /$ $\mathrm{cm}^{2}$ on 8 points around the knee joint. The selected eight points are the medial and lateral epicondyles of the tibia and femur, the medial and lateral knee joint gap, and the medial edge of the tendon of the biceps femoris and semitendinosus muscles in the popliteal fossa. Laser therapy was administered 2 times/week for 8 weeks with a low power laser (power $50 \mathrm{~mW}$, continuous wave, wavelength $880 \mathrm{~nm}$ ). Each point received energy of $6 \mathrm{~J} /$ point for 60 seconds, with a total dose of $48 \mathrm{~J}$ in each session. ${ }^{12,18}$ Group-II

After patient preparation as in group-I, each patient received a LLLT dose of $3 \mathrm{~J} / \mathrm{cm}^{2}$ with the knee extended. The laser energy was irradiated over the joint line onto five points of the synovial region of the medial side of the knee and in four points at the lateral side, at $3 \mathrm{~J}$ per point. Total dose was $27 \mathrm{~J}$ per session and used previously calibrated equipment (Irradia Class 3B; Stockholm, Sweden). The pen's semi-conductor consisted of gallium arsenide with wavelength of $904 \mathrm{~nm}$, frequency of $700 \mathrm{~Hz}$, average power of $60 \mathrm{~mW}$, peak power of $20 \mathrm{~W}$, pulse duration 4.3 $\mathrm{ms}, 50$ seconds per point (area $0.5 \mathrm{~cm}^{2}$ ). The parameters followed the recommendation of the World Association of Laser Therapy (WALT) 19 for OA. ${ }^{23}$

\section{Group-III}

For each patient in the placebo group, procedure was identical but without emission of energy. The laser equipment had two identical pens, one for the active treatment and one for the placebo treatment (sealed).

\section{Exercise Training Program}

All patients of three groups participated on the same following exercise training program for 30 to 45 minutes 2 sessions/week for 8 weeks.

1-Stretching for the quadriceps, hamstrings, adductors, and calf muscles for 30 seconds, relaxation for $10 \mathrm{sec}$ onds and repeated 3 times; Total time of stretching $\approx 5$ minutes. ${ }^{23}$

2-Strengthening exercises included knee extension, straight leg raising and quadriceps setting exercise. The contraction was maintained for 6 seconds followed by relaxation for 10 seconds and repeated 8 times/set in each exercise.

NB: These exercises were performed in three sets, eight repetitions. Resistance was determined to be $30 \%$ of 1 repetition maximum. All participants were instructed to practice these exercises as a home program..$^{29,34,35}$ Photographic details of the home-based exercises were distributed to each patient with a dairy log book. Patients were encouraged regarding compliance with the exercise to record number of days the exercises were performed/week. All patients were advised to keep their activity level and medication unchanged throughout the study period.

Statistical Analysis

The collected data were statistically analyzed using SPSS package (version 20.0). Paired t test was used to determine significant improvements within each group. Analysis of 
variance (ANOVA) test was used to detect the significance differences among three groups after physical therapy interventions. LSD test was used to determine any group that had the best significant improvements. $P<0.05$ are considered statistically significant and at CI 95\%.

\section{Results}

Demographic Data of Patients

A total of 51 older patients $(35.3 \%$ males and $64.7 \%$ female) completed this study. All of them had chronic knee OA for $\geq 3$ years, $23.5 \%$ of them with bilateral knee OA (both limb was treated but statistical analysis was done for the worst one), $49.0 \%$ with right and $27.0 \%$ with left knee OA. $64.7 \%$ of patients with grade-II and $35.3 \%$ of patients with grade-III. Patients were assigned randomly into three groups: Group-I: 18 patients ( 7 males $\& 11$ females) received laser $6 \mathrm{~J} / \mathrm{cm}^{2}$. Group-II: 18 patients $(6$ males \& 12 females) received laser $3 \mathrm{~J} / \mathrm{cm}^{2}$. Group-III: 15 (5 males $\& 10$ females) patients received laser without emission as placebo. Also every patient of the three groups practiced the same exercise program. Pre-physical therapy interventions ANOVA test showed that there were non-significant differences in the demographic data among three groups (Table 1).

Pain Intensity and Physical Function Activity

Mean values of VAS and WOMAC knee pain and stiffness reduced significantly in three groups after physical therapy interventions $(P<0.05$; Figure 2$)$, also ANOVA analysis proved that there were significant differences regarding VAS, WOMAC pain \& stiffness among them after physical therapy interventions $(P<0.05$; Table 2$)$. The post hoc tests (LSD) proved that the best improvements in VAS, WOMAC pain, knee stiffness and physical function was for patients who received $6 \mathrm{~J} / \mathrm{cm}^{2}$ then $3 \mathrm{~J} / \mathrm{cm}^{2}$ and placebo group was the lowest.

Physical Function, Knee Mobility and Isometric Strength Mean values of physical function significantly reduced in WOMAC, which means improvement in physical function while isometric strength of the quadriceps and hamstring muscles increased significantly in three groups after interventions $(P<0.05$; Figure 3$)$. In addition, ANOVA analysis proved that there were significant differences among them after physical therapy interventions $(P<0.05$; Table 3). Also LSD showed that the highest increase in iso-

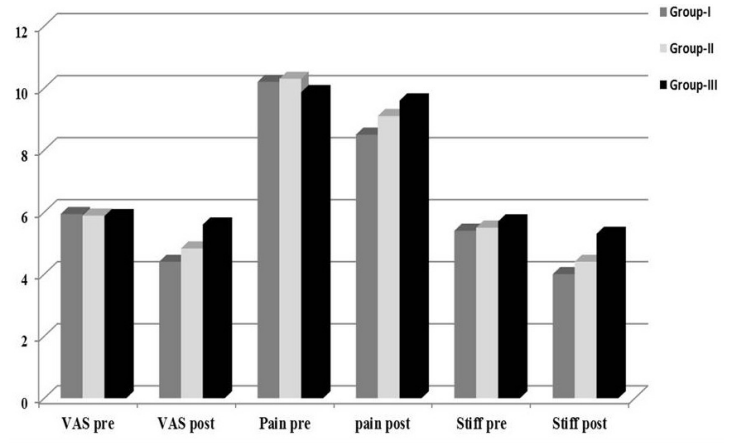

Figure 2. Mean Values of VAS and WOMAC Knee Pain and Stiffness Among Three groups Pre- and Post-physical Therapy Interventions. VAS, visual analogue scale; Pain, WOMAC pain assessment; Stiff, knee Stiffness.

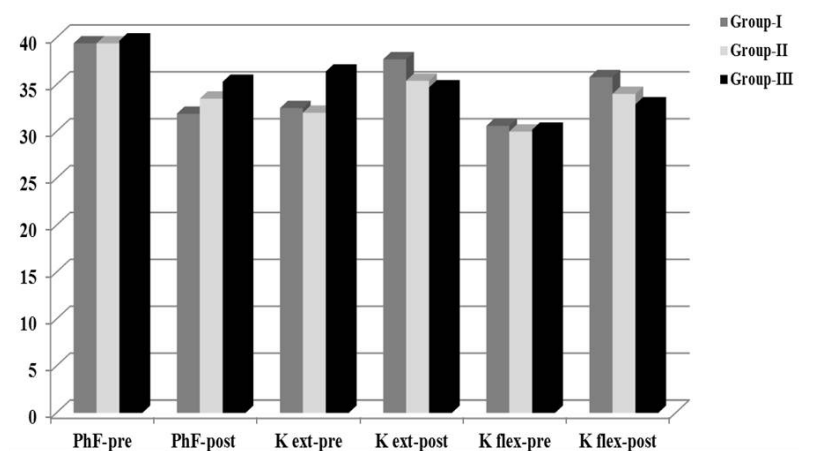

Figure 3. Mean Values of Knee Physical WOMAC questionnaire, Isometric muscle Strength of Knee Extensors and Flexors Among Three groups Pre- and Post-physical Therapy Interventions. PhF: physical function of the knee joint (its reduction in WOMAC means improvement); $\mathrm{K}$ ext: knee extensors; $\mathrm{K}$ flex; knee flexors.

metric strength of the quadriceps and hamstring muscles and knee flexion range of motion (ROM) was for patients who received $6 \mathrm{~J} / \mathrm{cm}^{2}$ then $3 \mathrm{~J} / \mathrm{cm}^{2}$ and placebo group. Whereas mean values of knee flexion ROM increased significantly from $116.83 \pm 2.38,116.33 \pm 1.85,117.6 \pm 2.4$, to $125.83 \pm 3.3,122.29 \pm 2.4,123.5 \pm 2$. 8 , after physical therapy interventions in group-I, II, and III respectively with significant differences among them $(\mathrm{F}$ value $=1.34$ \& 1.46; $P<0.05$; Table 3 ).

\section{Discussion}

Knee OA is one of the most common disabling painful conditions in rheumatology practice, ${ }^{19,9,36}$ and it is a significant disabling problem for older subjects. ${ }^{2,5,37,38}$ The

Table 1. Demographic Data of Patients Study Sample

\begin{tabular}{|c|c|c|c|c|c|}
\hline \multirow{2}{*}{ Variables } & Group-I & Group-II & Group-III & \multirow{2}{*}{ F Value } & \multirow{2}{*}{$P$ Value } \\
\hline & Mean \pm SD & Mean \pm SD & Mean \pm SD & & \\
\hline Age & $67.3 \pm 2.9$ & $67.5 \pm 2.5$ & $66.3 \pm 3.2$ & 1.13 & $0.33^{a}$ \\
\hline BMI & $26.8 \pm 1.9$ & $27.0 \pm 2.4$ & $27.5 \pm 1.9$ & 0.39 & $0.68^{\mathrm{a}}$ \\
\hline Duration & $5.2 \pm 1.5$ & $5.1 \pm 1.5$ & $5.6 \pm 1.2$ & 0.44 & $0.65^{a}$ \\
\hline Sex & 7 males, 11 females & 6 males, 12 females & 5 males, 10 females & 1.49 & $0.23^{\mathrm{a}}$ \\
\hline OA degree & Grade- $\mathrm{II}=12$, Grade- $\mathrm{III}=6$ & Grade- $I I=11$, Grade- $I I I=7$ & Grade- $I I=10$, Grade- $I I I=5$ & 0.07 & $0.93^{\mathrm{a}}$ \\
\hline Affected side & 4 left, 9 right, 5 Both & 6 left, 7 right, 5 Both & 4 left, 9 right, 2 Both & 0.28 & $0.76^{\mathrm{a}}$ \\
\hline
\end{tabular}

Abbreviations: BMI, body mass index; OA, Osteoarthritis.

a Non-significant $P>0.05$. 
Table 2. Comparison of VAS and WOMAC Questionnaire Among Three Groups Pre- and Postphysical Therapy Interventions

\begin{tabular}{lcccc}
\hline Variables & $\begin{array}{c}\text { Sum of } \\
\text { squares }\end{array}$ & $\begin{array}{c}\text { Mean } \\
\text { Squares }\end{array}$ & F Value & P Value \\
\hline VAS - pre & 0.054 & 0.027 & 0.06 & $0.94^{\mathrm{a}}$ \\
VAS - post & 7.47 & 3.74 & 9.04 & $0.00^{\mathrm{b}}$ \\
Pain - pre & 1.9 & 0.95 & 0.56 & $0.57^{\mathrm{a}}$ \\
Pain - post & 7.02 & 3.51 & 3.84 & $0.028^{\mathrm{b}}$ \\
Stiffness - pre & 0.03 & 0.014 & 0.021 & $0.98^{\mathrm{a}}$ \\
Stiffness - post & 4.54 & 2.27 & 5.63 & $0.006^{\mathrm{b}}$ \\
Physical - pre & 2.8 & 1.39 & 0.2 & $0.82^{\mathrm{a}}$ \\
Physical - post & 94.0 & 47.0 & 14.0 & $0.00^{\mathrm{b}}$ \\
\hline
\end{tabular}

Abbreviations: VAS, visual analogue scale; WOMAC, Western

Ontario and McMaster Universities Osteoarthritis.

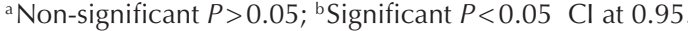

Table 3. Comparison of Isometric Knee Extensors, Flexors Muscles Strength and Knee Flexion Range of Motion pre- and Postphysical Therapy Interventions Among Three Groups

\begin{tabular}{lcccc}
\hline Variables & $\begin{array}{c}\text { Sum of } \\
\text { Squares }\end{array}$ & $\begin{array}{c}\text { Mean } \\
\text { Squares }\end{array}$ & F Value & $\boldsymbol{P}$ Value \\
\hline Knee extension - pre & 9.21 & 4.1 & 0.29 & $0.75^{\mathrm{a}}$ \\
Knee extension- post & 91.67 & 45.84 & 3.36 & $0.043^{\mathrm{b}}$ \\
Knee flex- pre & 2.96 & 1.48 & 0.35 & $0.57^{\mathrm{a}}$ \\
Knee flex- post & 71.7 & 35.87 & 8.66 & $0.001^{\mathrm{b}}$ \\
Knee flex ROM -pre & 13.19 & 6.59 & 1.34 & $0.27^{\mathrm{a}}$ \\
Knee flex ROM -post & 514.3 & 257.2 & 46.76 & $0.001^{\mathrm{b}}$ \\
\hline
\end{tabular}

Abbreviation: ROM, range of motion.

a Non-significant $P>0.05$; ${ }^{b}$ Significant $P<0.05 \mathrm{Cl}$ at 0.95 .

results obtained in the current study proved that adding LLLT to exercise training program could be an important modality for treating older persons with OA than exercise training alone. The active laser groups either $6 \mathrm{~J} / \mathrm{cm}^{2}$ or 3 $\mathrm{J} / \mathrm{cm}^{2}$ had a significant reduction of pain intensity in VAS and WOMAC, increase in physical function, increase in isometric quadriceps and hamstring muscle strength, and increase in range of motion after treatment of knee OA.

LLLT is considered a safe and applicable modality for patients with knee OA. ${ }^{12,17,18}$ Its usage is supported either in middle-aged subjects ${ }^{10}$ or for particular older subjects ${ }^{12,23}$ where the usage of drugs is more restricted. Effects of LLLT on knee OA has been studied, but the results are still in conflict. The results of this study were corroborated by these studies. ${ }^{12,17,18,23,39}$ The reduction of pain intensity and increase in physical function by LLLT was confirmed in many previous clinical studies. ${ }^{17,23}$ Hegedus et al ${ }^{17}$ applied active LLLT or placebo LLLT in double blind, randomized, placebo-controlled trial. Patients received treatment twice a week over a 4 -week period, continuous wave and dose of $6 \mathrm{~J} / \mathrm{cm}^{2}$ that was similar to the LLLT dose in the current study in group-I. The authors found that patients treated with the active diode laser demonstrated significant improvements in pain, knee circumference, point pressure sensitivity, and knee flexion compared with the placebo group. In addition some investigators applied the laser acupuncture for a 2 -week (10 sessions) on the medial side of the arthritic knee. They found that laser acupuncture was more effective in reducing per articular swelling when compared with placebo laser in knee OA. ${ }^{39}$ In agreement with the current study, adding low level laser to exercise program for patients with knee OA was recommended. ${ }^{18,23}$ The authors in Alfredo et $\mathrm{al}^{23}$ study compared laser group (LLLT dose of $3 \mathrm{~J} / \mathrm{cm}^{2}$ and exercises) or placebo group (placebo laser and exercises). The dose of $3 \mathrm{~J} / \mathrm{cm}^{2}$ has been applied in the current study on group II. They found LLLT when associated with exercises results in more pain relief, improvements in function activity compared with placebo group that received exercises only. That means, adding laser therapy to exercise training magnifies the physiological effects of each other as the anti-inflammatory effects of laser and its analgesic effects reflected on the physical function and muscle power and vice versa. Thus it is can be suggested that exercise training alone is not sufficient for the treatment of chronic knee OA particular in older patients, but should be used in combination with any other anti-inflammatory physical therapy modality.

In a recent study of LLLT on knee OA they, found that active laser on eight points that received dosage of $6 \mathrm{~J} /$ point for 60 seconds, with a total dosage of $48 \mathrm{~J} / \mathrm{cm}^{2}$ in each session two times per week over the period of 4 weeks showed significant differences in pain relief and functional performance in patients with chronic knee OA in comparison with placebo group. ${ }^{18}$ In that study, all patients practiced home-based exercise program in addition to laser application, ${ }^{18}$ while in the current study, the authors applied supervised exercise program in the treatment session and asked patients to repeat it at home.

In contrast to the findings of this study, some clinical trials found non-significant improvement in pain intensity and WOMAC index in patients receiving gallium/aluminum/arsenide (GA-Al-As) laser $830 \mathrm{~nm}$ with dose ranging from 1.5 to $3 \mathrm{~J} / \mathrm{cm}^{2}{ }^{19}$ Differences in results may be attributed to some differences in treatment plan and the low laser dose. The treatments with LLLT in this study were 12 sessions/ 2 sessions/week for 8 weeks. However in Tasciloglu et $\mathrm{al}^{19}$ study, there was only 10 treatment sessions/once a day, five days a week for a total duration of 10 days. In addition, in this study the patients received exercise program beside laser dose, while in Tasciloglu et $\mathrm{al}^{19}$ study, patients were treated by laser only.

In conflict to the current study also, others investigators evaluated LLLT in 88 patients with hand OA. Treatment was applied using a gallium-aluminum-arsenide diode laser 3 times/week for 6 weeks. They found that there were no significant differences in pain quality between the active treatment group and the control group. ${ }^{40}$ This may be attributed to differences in nature of arthritic changes and number of sessions of treatment. ${ }^{40}$ Another different factor for contrast is the difference between the gallium-aluminum-arsenide diode laser used in their work ${ }^{40}$ and the gallium-arsenide diode laser used in this study. The contradictions in the literature of LLLT benefits may be attributed to variations in treatment parameters by LLLT, such as wavelength, power, energy density, number, and duration of treatment, size of exposure area, and method 


\section{of laser administration. ${ }^{18}$}

Regarding the dose of laser applied, in this study, the authors found that application of $6 \mathrm{~J} / \mathrm{cm}^{2}$ was more effective than $3 \mathrm{~J} / \mathrm{cm}^{2}$ during treatment of patients with OA knee. In agreement with the idea of application of laser dose in treatment of $\mathrm{OA}$, some investigators compared $3 \mathrm{~J} / \mathrm{cm}^{2}$ and $2 \mathrm{~J} / \mathrm{cm}^{2}$. The authors found $3 \mathrm{~J} / \mathrm{cm}^{2}$ showed a tendency to be better than $2 \mathrm{~J} / \mathrm{cm}^{2}{ }^{26}$ In another report, active laser dosage of $3 \mathrm{~J} / \mathrm{cm}^{2}$ per painful point and active laser with a dosage of $1.5 \mathrm{~J} / \mathrm{cm}^{2}$ per painful point gave non-significant effects. ${ }^{19}$ Other published trials compared active laser $3 \mathrm{~J} / \mathrm{cm}^{2}$ with placebo ${ }^{23}$ or dosage of $6 \mathrm{~J} / \mathrm{cm}^{2}$ with placebo $^{18}$ and found significant improvement with active laser for both doses compared to placebo. ${ }^{18,23}$

Some of the mechanisms behind laser effects on musculoskeletal system are still unclear. ${ }^{18}$ The reduction of pain achieved by LLLT could be explained by an increase in neurotransmitters' levels, including serotonin, which is important in endogenous pain modulation. ${ }^{41}$ Several studies have reported positive effects from LLLT including influences on fibroblast propagation, osteoblast production, and collagen synthesis as well as revascularization in wound healing. ${ }^{10}$ In addition, it has a positive effect on modulation of inflammation ${ }^{13,14,42}$ and stimulation of angiogenesis as well as in the reduction of fibrosis formation. ${ }^{15}$ Improvements of physical joint function outcomes usually occur as a consequence of pain intensity reduction, as pain reduction is usually primarily responsible for improvements in muscle function. ${ }^{43}$

Application of exercise training programs for treatment of $\mathrm{OA}$ is proved to provide more efficiency in patient's care ${ }^{29,34,44}$ The Ottawa Panel recommends application of active therapeutic exercises alone, or in combination with manual therapy, in management of patients with OA. ${ }^{45}$ There is good evidence that exercise can reduce pain and improve joint physical function in patients with OA. ${ }^{35,37,38,46}$ In a recent publication on the benefits of exercises on OA it was suggested that all grades of OA severity can benefit from professionally supervised exercise therapy. ${ }^{30}$

Resistance exercise has been shown to be effective in pain reduction and improving physical functional activity. This mode of exercise may restore muscle strength and joint mechanics while improving physical function. It may normalize muscle firing patterns and joint biomechanics leading to reductions in arthritic joint pain and cartilage degradation. ${ }^{47}$ This may explain improvements in pain and physical function, mobility and muscle power in exercise group. Our findings suggest that analgesia induced by LLLT in addition to supervised exercise program resulted in more improvements in pain, physical function of older subjects with OA.

\section{Limitations}

The current study had some limitations, e.g. the small sample size. So, further studies with larger sample size are necessary to provide a much better insight into the effectiveness of LLLT. Also the short-term follow-up is another limitation of this study. Therefore; further studies should be conducted to evaluate the long-term effect of LLLT on pain relief and functional improvement on elderly subjects with OA knee.

\section{Recommendations}

The application of low level laser 2 sessions/week for 8 weeks can be an integral part in the management of patients with chronic knee OA. Comparisons of different intensities of LLLT on larger samples and for longer periods are recommended. The combination of laser and exercise training can achieve further improvements in pain, physical function and knee mobility, and isometric strength of quadriceps in older subjects with knee OA.

\section{Conclusion}

It can be concluded that adding LLLT to exercise training program is more effective than exercise training alone in the treatment of patients with chronic knee OA and the rate of improvements may be dose dependent, as with 6 $\mathrm{J} / \mathrm{cm}^{2}$ or $3 \mathrm{~J} / \mathrm{cm}^{2}$.

\section{Ethical Considerations}

Our protocol was approved by the Ethical Committee Board, Faculty of Physical Therapy Cairo University. Sixty patients fulfilled the entry criteria and enrolled to the study. They were informed that the recorded data would be submitted for publication and they signed an informed consent form. They were assigned randomly to three groups by a blinded and independent research assistant who opened sealed envelopes that contained a computer-generated randomization card according to the recruitment diagram.

\section{Conflict of Interest}

The authors declare no conflict of interests.

\section{References}

1. Gottlieba T, Jorgensenb B, Rohdec E, Mullerc G, Schellera E. The influence of irradiation with low-level diode laser on the proteoglycan content in arthritically changed cartilage in rabbits. Med Laser Appl. 2006;21:53-59.

2. Chen D. Updated therapy in elderly patients with Knee osteoarthritis. Int J Gerontol. 2007;(1):31-39. doi:10.1016/ s1873-9598(08)70021-8.

3. Messier SP, Gutekunst DJ, Davis C, DeVita P. Weight loss reduces knee-joint loads in overweight and obese older adults with knee osteoarthritis. Arthritis Rheum. 2005;52(7):2026-2032. doi:10.1002/art.21139.

4. Vaapio S, Salminen M, Vahlberg T, et al. Effects of riskbased multifactorial fall prevention on health-related quality of life among the community-dwelling aged: a randomized controlled trial. Health Qual Life Outcomes. 2007;26:(5):20-25. doi:10.1186/1477-7525-5-20.

5. Blagojevic M, Jinks C, Jeffery A, Jordan KP. Risk factors for onset of osteoarthritis of the knee in older adults: a systematic review and meta-analysis. Osteoarthritis Cartilage. 2010;18(1):24-33. doi:10.1016/j. joca.2009.08.010.

6. Gupta S, Hawker GA, Laporte A, Croxford R, Coyte 
PC. The economic burden of disabling hip and knee osteoarthritis (OA) from the perspective of individuals living with this condition. Rheumatology. 2005;44:15311537. doi: 10.1093/rheumatology/kei049.

7. Braddom RL. Physical Medicine \& Rehabilitation. 3rd ed. New York: Elsevier; 2012.

8. Jordan KM, Arden NK, Doherty M, Bannwarth B, Bijlsma JW, Dieppe P. EULAR Recommendations 2003: an evidence-based approach to the management of knee osteoarthritis: Report of a Task Force of the Standing Committee for International Clinical Studies Including Therapeutic Trials (ESCISIT). Ann Rheum Dis. 2003;62:1145-1155. doi:10.1136/ard.2003.011742.

9. Hay EM, Foster NE, Thomas E, et al. Effectiveness of community physiotherapy and enhanced pharmacy review for knee pain in people aged over 55 presenting to primary care: pragmatic randomized trial. BMJ. 2006;333:995. doi:10.1136/bmj.38977.590752.0b.

10. Adams T, Band-Entrup D, Kuhn S, et al. Physical therapy management of knee osteoarthritis in the middle-aged athlete. Sports Med Arthrosc. 2013;21(1):2-10. doi:10.1097/ jsa.0b013e318272f530.

11. Luksurapan W, Boonhong JB. Effects of phonophoresis of piroxicam and ultrasound on symptomatic knee osteoarthritis. Arch Phys Med Rehabil. 2013;94(2):250-255.

12. Rayegani SM, Bahrami HM, Elyaspour D, Saeedi M, Sanjari H. Therapeutic effects of low level laser therapy (LLLT) in knee osteoarthritis, compared to therapeutic ultrasound. J Lasers Med Sci. 2012;3;2:71-74.

13. Alves AC, Vieira R, Leal-Junior E, et al. Effect of lowlevel laser therapy on the expression of inflammatory mediators and on neutrophils and macrophages in acute joint inflammation. Arthritis Res Ther. 2013;15(5):R116. doi: 10.1186/ar4296.

14. Castano AP, Dai T, Yaroslavsky I, et al. Low-level laser therapy for zymosan-induced arthritis in rats: Importance of illumination time. Lasers Surg Med. 2007;39(6):543-550. doi:10.1002/lsm.20516.

15. Da Rosa AS, dos Santos AF, da Silva MM, et al. Effects of low-level laser therapy at wavelengths of 660 and 808 $\mathrm{nm}$ in experimental model of osteoarthritis. Photochem Photobiol. 2012;88(1):161-166. doi:10.1111/j.17511097.2011.01032.x.

16. Gur A, Karakoc M, Cevik R, Nas K, Sarac AJ. Efficacy of low power laser therapy and exercise on pain and functions in chronic low back pain. Lasers Surg Med. 2003;32(3):233238. doi:10.1002/lsm.10134.

17. Hegedus B, Viharos L, Gervain M, Galfi M. The effect of low-level laser in knee osteoarthritis: a double blind, randomized, placebo-controlled trial. Photomed Laser Surg. 2009;27(4):577-584. doi:10.1089/pho.2008.2297.

18. Alghadir A, Omar MT, Al-Askar AB, Al-Muteri NK. Effect of low-level laser therapy in patients with chronic knee osteoarthritis: a single-blinded randomized clinical study. Lasers Med Sci. 2014;29:749-755.

19. Tasciloglu F, Armagan O, Tabek Y, Corapci I, Oner C. Low power laser treatment in patients with knee osteoarthritis. Swiss Med Wkly. 2004;134(17-18):254-258.

20. Brosseau L, Welch V, Wells G. Low Level laser therapy (Classes I, II, and III) for treating osteoarthritis. Cochrane Database Syst Rev. 2004;(3):CD002046. doi:10.1002/14651858.cd002046.

21. Bjordal JM, Johnson MI, Lopes-Martins RA. Short-term efficacy of physical interventions in osteoarthritic knee pain: a systematic review and meta-analysis of randomized placebo controlled trials. BMC Musculoskeletal Disord. 2007;8:51. doi:10.1186/1471-2474-8-51.

22. Brosseau L, Welch V, Wells G, Tugwell P, de Bie R, Gam A. Low level laser therapy for osteoarthritis and rheumatoid arthritis: a meta-analysis. J Rheumatol. 2000; 27(8):19611969. doi:10.1002/14651858.cd002046.pub3.

23. Alfredo PP, Bjordal MJ, Dreyer HS, et al. Efficacy of low level laser therapy associated with exercises in knee osteoarthritis: a randomized double-blind study. Clin Rehabil. 2012;26:523. doi:10.1177/0269215511425962.

24. Altman R, Asch E, Bloch D. Development of criteria for the classification and reporting of osteoarthritis. Classification of osteoarthritis of the knee. Diagnostic and Therapeutic Criteria Committee of the American Rheumatism Association. Arthritis Rheum. 1986;29:1039-1049.

25. Kellgren JH, Lawrence JS. Radiological assessment of osteoarthritis. Ann Rheum Dis. 1957;16:494-502.

26. Tak E, Staats P, Van Hespen A, Hopman-Rock M. The effects of an exercise program for older adults with osteoarthritis of the hip. J Rheumatol. 2005;32(6):1106-1113.

27. Bolognese JA, Schnitzer TJ, Ehrich EW. Response relationship of VAS and Likert scales in osteoarthritis efficacy measurement. Osteoarthr Cartil. 2003;11(7):499507. doi:10.1016/s1063-4584(03)00082-7.

28. Scrimshaw S, Maher C. Responsiveness of visual analogue and McGill pain scale measures. J Manipulative Physiol Ther. 2001;24(8):501-504. doi:10.1067/mmt.2001.118208.

29. Deyle GD, Allison SC, Matekel RL, et al . Physical therapy treatment effectiveness for osteoarthritis of the knee: a randomized comparison of supervised clinical exercise and manual therapy procedures versus a home exercise program. Phys Ther. 2005;85:1301-1317.

30. Knoop J, Dekker J, Van Der et al. Is the severity of knee osteoarthritis on magnetic resonance? Imaging associated with outcome of exercise therapy? Arthritis Care Res (Hoboken). 2014;66(1): 63-68. doi:10.1002/acr.22128.

31. Brosseau L, Balmer S, Tousignant $M$, et al. Intra- and intertester reliability and criterion validity of the parallelogram and universal goniometers for measuring maximum active knee flexion and extension of patients with knee restrictions. Arch Phys Med Rehabil. 2001;82(3):396402. doi:10.1053/apmr.2001.19250.

32. Gerhardt JJ, Rondinelli RD Goniometric techniques for range-of-motion assessment. Phys Med Rehabil Clin N Am. 2001;12(3):507-527.

33. Piva SR, Goodnite EA, Childs JD. Strength around the hip and flexibility of soft tissues in individuals with and without patella-femoral pain syndrome. J Orthop Sports Phys Ther. 2005;35:793-801. doi:10.2519/jospt.2005.35.12.793.

34. Knoop J, Dekker J, van der Leeden M, et al. Knee joint stabilization therapy in patients with osteoarthritis of the knee: a randomized, controlled trial. Osteoarthritis Cartilage. 2013;21:1025-1034.

35. Abbott JH, Robertson MC, McKenzie JE, et al. Exercise therapy, manual therapy, or both, for osteoarthritis of the hip or knee: a factorial randomized controlled trial protocol. Trials. 2009;10:11. doi:10.1186/1745-6215-10-11.

36. Bjordal JM, Couppe C, Chow RT, Turner J, Ljunggren EA. A systematic review of low-level laser therapy with locationspecific doses for pain from chronic joint disorders. Austr J Physiother. 2003;49:107-116. 
37. Bosomworth NJ. Exercise and knee osteoarthritis: benefit or hazard? Can Fam Physician. 2009;55(9):871-878.

38. Ringdahl E, Pandit S. Treatment of knee osteoarthritis. Am Fam Physician. 2011;83(11):1287-1292.

39. Yurtkuran M, Alp A, Konur S, Ozçakir S, Bingol U. Laser acupuncture in knee osteoarthritis: a double-blind, randomized controlled study. Photomed Laser Surg. 2007; 25(1):14-20

40. Brosseau L, Wells G, Marchand S, et al. Randomized controlled trail on low-level laser therapy in the treatment of osteoarthritis of the hand. Lasers Surg Med. 2005; 36(3):210-19.

41. Brosseau L, Milne S, Robinson V, Marchand S. Efficacy of the transcutaneous electrical nerve stimulation for the treatment of chronic low back pain: a meta-analysis. Spine. 2002:27(6):596-603. doi:10.1002/lsm.20137

42. Marovino T. Cold lasers in low-level laser therapy pain management. Practical Pain Management. 2004.

43. Hassan BS, Doherty SA, MockettS, Doherty M. Effect of pain reduction on postural sway, proprioception, and quadriceps strength in subjects with knee osteoarthritis. Ann Rheum Dis. 2001;61(5):422-428. doi:10.1136/ ard.61.5.422.

44. Jansen MJ, Viechtbauer W, Lenssen AF, Hendriks EJ, de Bie RA. Strength training alone, exercise therapy alone, and exercise therapy with passive manual mobilization each reduce pain and disability in people with knee osteoarthritis: a systematic review. J Physiother. 2011;57(1):11-20.

45. Brosseau L, Wells G, Tugwell P, Egan M, Dubouloz C. Ottawa panel evidence-based clinical practice guidelines for therapeutic exercises and manual therapy in the management of osteoarthritis. Phys Ther. 2005;85(9):907971.

46. Iversen MD. Managing hip and knee osteoarthritis with exercise: what is the best prescription? Ther $A d v$ Musculoskelet Dis. 2010;2(5):279-290.

47. Vincent KR, Vincent HK. Resistance exercise for knee osteoarthritis. PM R. 2012;4(5 Suppl):S45-S52. doi:10.1016/j.pmrj.2012.01.019. 